\title{
PEMANFAATAN HANDLE GRINDER SEBAGAI MESIN PENCACAH PAKAN TERNAK MULTI FUNGSI
}

\author{
Bambang Minto Basuki ${ }^{1}$, Nur Robbi ${ }^{2}$ \\ ${ }^{1}$ Teknik Elektro, Fakultas Teknik, Universitas Islam Malang \\ ${ }^{2}$ Teknik Mesin, Fakultas Teknik, Universitas Islam Malang \\ Jl. MT. Haryono no 193 Malang \\ bambang.minto@unisma.ac.id ${ }^{1}$,nurrobbi@unisma.ac.id ${ }^{2}$
}

\begin{abstract}
ABSTRAK
Masyarakat Desa babadan yang berada di Kecamatan Ngrambe Kab, Ngawi memiliki warga yang $90 \%$ bermatapencaharian petani dan pekebun. Selain itu mereka juga memiliki usaha tambaan berupa beternak sapi, kambing, kelinci, entok dan bebek. Dalam penyediaan pakan ternak, mereka menggunakan bahan tambahan berupa ubi jalar, batang pisang dan aneka bahan lain yang harus dicacah halus. Hal ini membutuhkan waktu yang lama berkisar 1-1,5 jam tiap harinya. Untuk itu perlu dibantu dengan pemanfaatan mesin cacah pakan ternak yang berkemampuan tinggi dan berdaya listrik rendah. Dengan memanfaatkan handle grinder sebagai penggerak mesin pencacah maka dperoleh hasil yang diharapkan berupa mesin pencacah pakan ternak dengan hasil cacahan yang halus dan membutuhkan waktu kerja yang singkat berkisar 5-10 menit per hari.
\end{abstract}

Kata Kunci: mesin pencacah, handle grinder, pakan ternak, desa babadan, petani

\begin{abstract}
Babadan Village community in Ngrambe District, Ngawi has residents, $90 \%$ of whom are farmers and planters. In addition, they also have an additional business in the form of growing cows, goats, rabbits, wild duck and ducks. In providing animal feed, they use additional ingredients in the form of sweet potatoes, banana stem and various other ingredients that must be finely chopped. This requires a long time ranging from 1-1.5 hours a day. For this reason, it is necessary to assist with the use of chopper machine with high capability and low electrical power. By utilizing the handle grinder as a chopper engine, the expected results will be in the form of an animal feed chopper with fine chopping results and requires a short working time of around 5-10 minutes a day.
\end{abstract}

Keywords: chopper, handle grinder, animal feed, babadan village, farmer

\section{PENDAHULUAN}

Desa babadan yang berada di Kecamatan Ngrambe Kab, Ngawi memiliki warga yang $90 \%$ bermatapencaharian petani dan pekebun. Selain itu mereka juga memiliki usaha tambaan berupa beternak sapi, kambing, kelinci, entok dan bebek. Data yang diperoleh dari lapangan, jumlah petani 1472 orang, peternak entok 21 orang, peternak ayam kampung 34 orang, peternak kelinci 6 orang. Jumlah ternak sapi dalam 1 desa 31 ekor, ternak kambing 64 ekor. Ternak kelinci 47 ekor. 
Selama ini para peternak yang tergabung dalam Gapoktan Sri widodo memberikan pakan pada hewan peliharaannya dengan cara memotong kecil-kecil secara manual berbagai tanaman yang dibutuhkan ternaknya. Waktu yang dibutuhkan berkisar 1 jam hingga 1,5 jam tergantung jumlah ternak dan jenisnya.

Biasanya penduduk desa Babadan melakukan beberapa pekerjaan sekaligus selain beternak seperti bertani dan berkebun karena itu jika waktu memproses pakan ternak bisa dipercepat, maka waktu lainnya bisa digunakan untuk pekerjaan lain. Dengan demikian penghasilan mereka akan meningkat.

Tujuan khusus kegiatan adalah : 1. Membantu sistem mekanisasi pakan ternak mitra sehingga mempersingkat waktu pembuatannya. 2. Memberikan pengetahuan tentang pemakaian mesin pencacah hasil kegiatan kepada mitra.

Target khusus yang ingin dicapai : 1. Tersedianya mesin pencacah multifungsi yang memanfaatkan handle grinder. 2. Gapoktan di desa mitra mampu memanfaatkan mesin cacah hasil kegiatan.

Proses pembuatan pakan dari gedebog pisang, ubi jalar yg dilakukan secara manual menggunakan parang atau pisau.
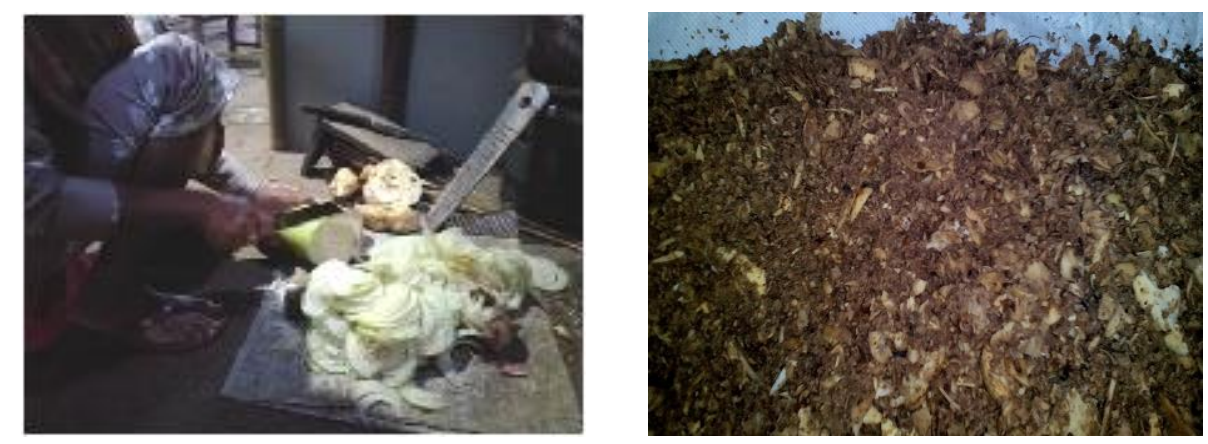

Gambar 1. Proses pencacahan pakan ternak yang masih manual dan hasilnya setelah dicampur dengan pakan pabrik serta bahan lainnya

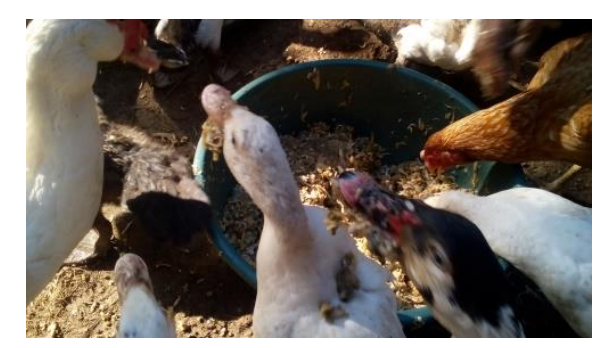

Gambar 2. Pakan yang dibuat kemudian diberikan ke ternak 
Hasil pengamatan di lapangan memperlihatkan bahwa berdasarkan kesepakatan dengan mitra, permasalahan yang dimiliki adalah :

1. Perlu waktu yang lama untuk menyiapkan pakan ternak dalam bentuk cacahan halus karena masih menggunakan cara manual dalam prosesnya

2. Jumlah pakan yang relatif sedikit saat musim kemarau.akibat kurangnya jumlah air hujan yang turun.

3. Pertumbuhan ternak kurang dari target yang diinginkan akibat dari mahalnya harga pakan yang dibutuhkan

4. Harga pakan buatan pabrik yang makin mahal.

Masalah yang diprioritaskan untuk diselesaikan selama kegiatan adalah adanya percepatan dalam mengolah pakan ternak khususnya dalam memperkecil ukuran pakan. Pakan ini nantinya masih akan dicampur dengan pakan buatan pabrik. Untuk itu perlu disediakan mesin pencacah rumput dan sumber pakan lainya.

\section{METODE}

Metode yang digunakan dalam kegiatan ini adalah dengan penerapan langsung mesin pencacah hasil kegiatan ke Gapoktan Sri Widodo, mengadakan pendikan dan latihan (diklat) terhadap pemakaian dan perawatan mesin cacah . Hasil kegiatan kemudian dipantau dan dianalisis untuk mendapatkan hasil yang maksimal dari kegiatan.

Target kegiatan adalah anggota Gapoktan Sri Widodo desa Babadan, Ngrambe, Ngawi. Luaran Kegiatan :

1. Terbangunnya mesin pencacah pakan ternak multifungsi yang memanfaatkan handle grinder.

2. Warga mitra mampu mengoperasikan dan merawat alat hasil kegiatan.

\section{HASIL DAN PEMBAHASAN}

Mesin cacah yang digunakan berupa mesin yang bertenaga listrik bertegangan 220V satu fasa , $50 \mathrm{~Hz}$, konsumsi daya bisa diatur (200W-600W). Daya listrik yang dimiliki warga desa rata-rata $450 \mathrm{~W}$ sehingga dengan mesin cacah yang dapat diatur dayanya akan dapat beroperasi dengan baik tanpa terganggu kekurangan pasokan listrik. Sistem berpenggerak mesin cacah berupa mesin gerinda tangan (handle grinder) berkecepatan tinggi 
yang dilengkapi pengatur kecepatan sehingga mampu berputar pada batas kecepatan $300 \mathrm{rpm}$ - $6000 \mathrm{rpm}$. Akibat dari pemakaian mesin berkecepatan tinggi tersebut maka hasil cacahan bisa diatur dari halus hingga kasar. Mesin cacah dapat digunakan pada 2 kondisi yaitu model cacah dan model potong. Pada model cacah, akan diperoleh hasil cacahan yang halus sedang pada model potong akan diperoleh hasil cacahan yang kasar .

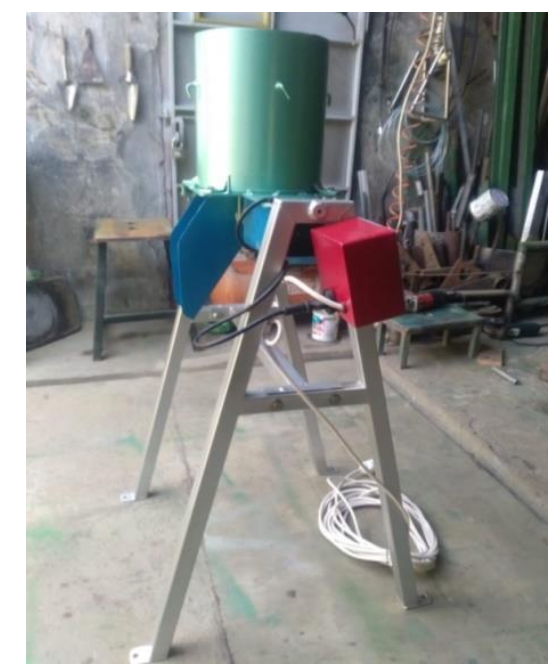

(a) Model Cacah

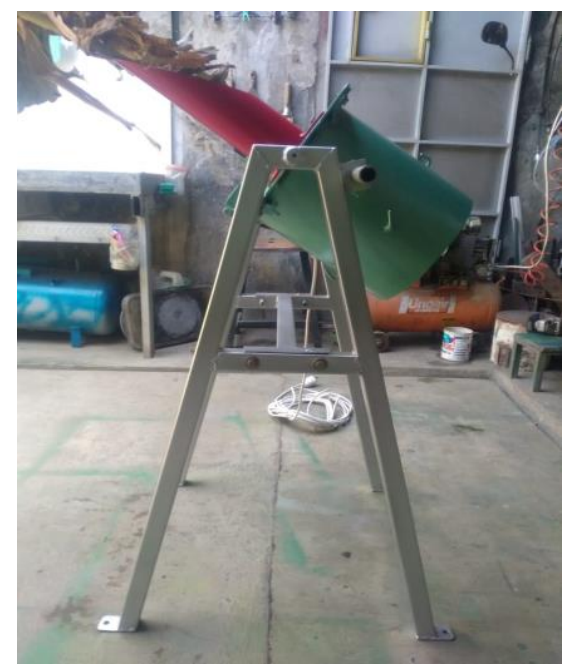

(b) Model Potong

Gambar 3 Mesin pencacah handle grinder pada kondisi cacah dan kondisi potong

Dimensi mesin dibuat kompak dengan tinggi $65 \mathrm{~cm}$, panjang $40 \mathrm{~cm}$, lebar $40 \mathrm{~cm}$ untuk mempermudah mobilitasnya. Hasil cacahan mesin dengan obyek berupa batang pisang dan daun pisang terdiri dari cacahan halus hingga kasar terlihat pada Gambar 4.

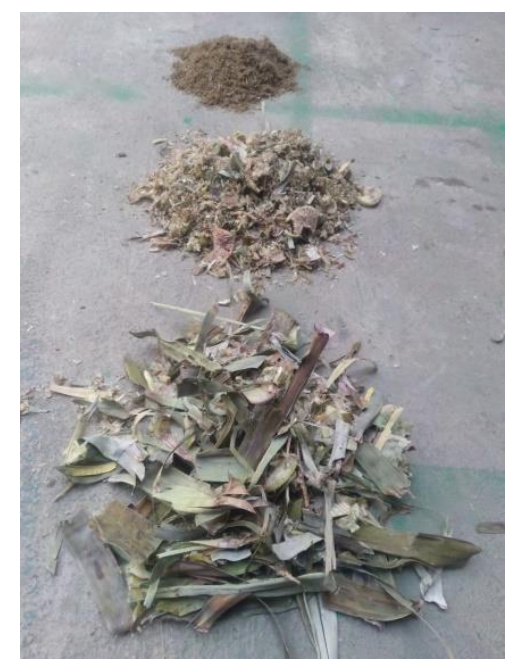

Gambar 4 . Hasil cacahan mesin 
Pada saat dilapangan dan diserahkan ke Gabungan kelompok tani (Gapoktan) Sri Widodo desa Babadan Kecamatan Ngrambe Kabupaten Ngawi, Mesin pancacah hasil kegiatan mampu mencacah rumput dan ubi jalar sebanyak $6 \mathrm{~kg}$ dalam 5 menit.
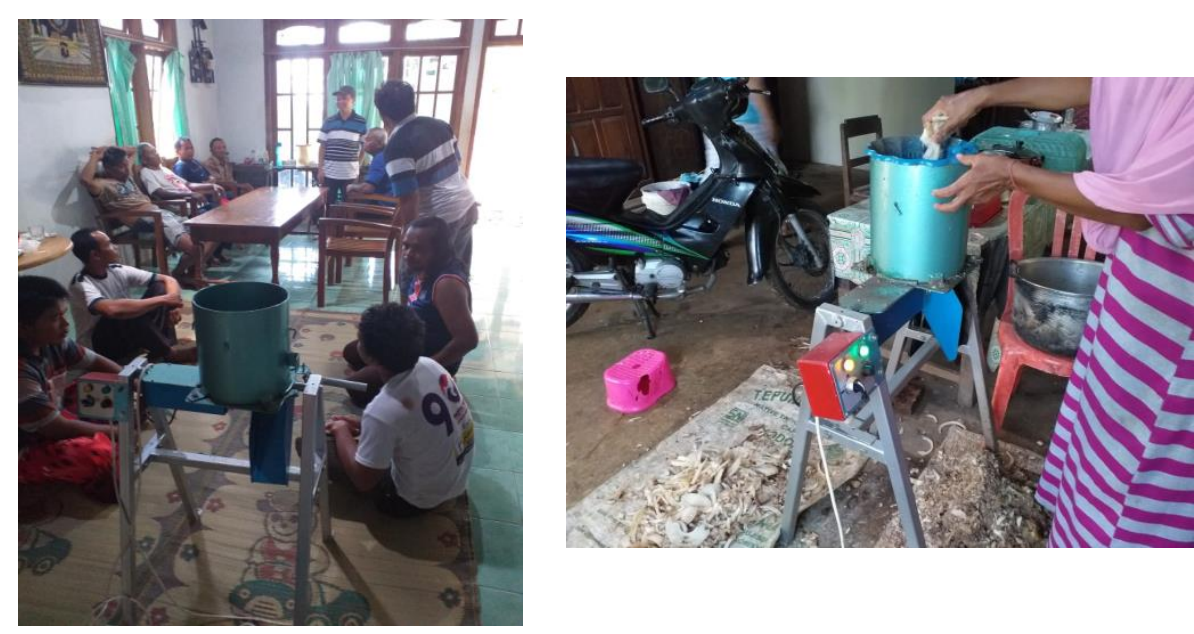

Gambar 5. Suasana Diklat di Gapoktan Sriwidodo dan Warga desa Mitra sedang memanfaatkan mesin hasil kegiatan

Hasil cacahan pakan kemudian dicampur dengan pakan pabrikan dan diberikan ke ternak mitra berupa ayam, bebek, mentok dan itik. Hasilnya, makanan tidak tersisa karena cacahannya sangat halus jauh berbeda dari hasil cacahan manual yang masih kasar sehingga ternak sulit memakannya.

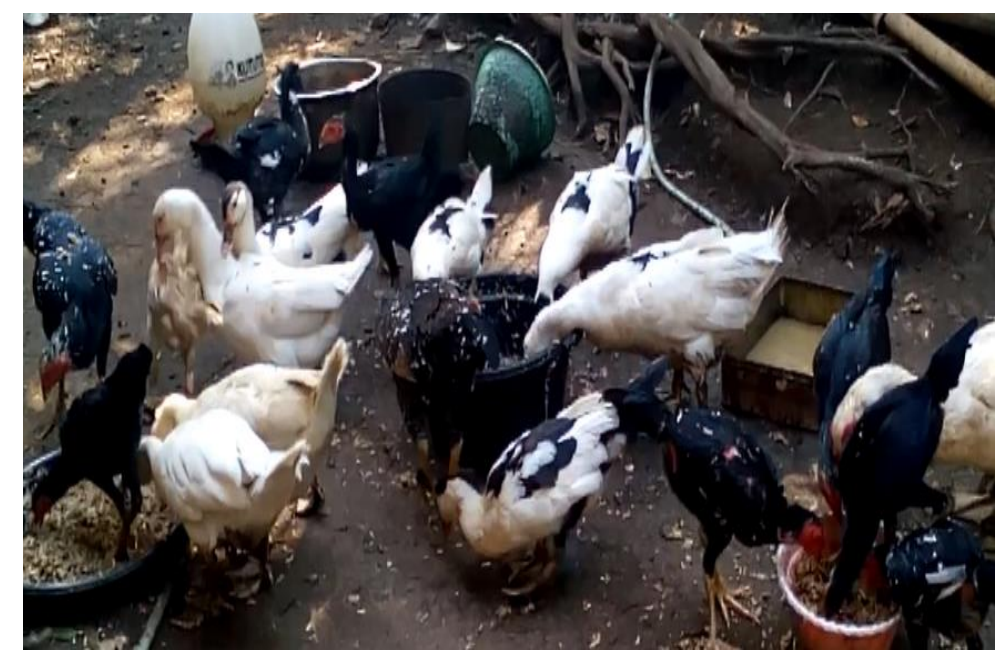

Gambar 6. Ternak mitra berebut makanan hasil cacahan mesin pencacah handle grinder 


\section{SIMPULAN}

Kesimpulan dari hasil kegiatan pengabdian masyarakat di desa Babadan, Ngrambe , Kab. Ngawi :

1. Masyarakat desa Mitra yang tgergabung dalam Gapoktan Sri Widodo desa Babadan merasa terbantu dalam penyediaan pakan ternak. Proses pencacahan yang biasanya berlangsung 30 - 60 menit / kg pakan menjadi 5 - 10 menit / kg pakan.

2. Masyarakat desa mitra mampu mengoperasikan mesin pencacah pakan ternak hasil kegiatan.

Saran :

Perlu dilakukan pemberian bantuan manajemen dan teknologi untuk pengembangan penjualan ternak hasil budidaya.

\section{DAFTAR PUSTAKA}

Andasuryani., Santosa., Chandra, Alhapen Ruslin. 2009. Membangun Mesin Pencacah Rumput Gajah Untuk Peningkatan Efektivitas Konsumsi Pakan Ternak Sapi. Artikel Ilmiah Pelaksanaan Program Pengabdian Program Vucer Tahun 2009

Baikhaky, Aby Al. 2015. Rancang Bangun Mesin Pencacah Botol Plastik. Tugas Akhir, Jurusan DIII Teknik Mesin, Universitas Diponegoro.

Hidayat,M,Harjono, Marsudi dan Andri G, 2006, Rancang Bangun Alat - Mesin Pencacah Jerami Padi Untuk Penyiapan Bahan Pakan Ternak.(Prosiding Seminar Nasional)

Husen, A. 2012. Modifikasi Mesin Pencacah Jerami. Tugas Akhir, Jurusan DIII Teknik Mesin. Universitas Diponegoro

Sularso. 1997. Dasar Perencanaan dan Pemilihan Elemen Mesin. Jakarta: Pradnya Paramita. 